\title{
Utilização do Cajueiro nas Ciências Médica, Veterinária e Higiene
}

\author{
Tonicley Alexandre da Silva, Priscila Sousa Barcellos, \\ Flavia Raquel Fernandes do Nascimento, Rosane Nassar Meireles Guerra \\ Departamento de Patologia da Universidade Federal do Maranhão, São Luís - MA - Brasil, CEP: 65065-080. \\ (roguerra@ufma.br)
}

\section{Objetivo}

Esta prospecção tecnológica visa fornecer ao pesquisador informações sobre as utilizações do cajueiro na classe de Ciências Médicas, Veterinárias e Higiene, oriundas de dados de documentos de patentes.

\section{Aspectos tecnológicos}

A espécie Anacardium occidentale L., popularmente conhecida como cajueiro, é nativa do Brasil com ampla distribuição na Região Nordeste do país. Os membros dessa espécie são árvores de copa baixa, com altura que varia entre 5 e $10 \mathrm{~m}$. Apresentam folhas simples, inteiras, oblongas, e flores róseas, pequenas, dispostas em panículas terminais. O nome caju é oriundo da palavra indígena acaiu e corresponde à parte carnosa que é um pseudofruto formado pelo pedúnculo do fruto. $O$ fruto é uma noz popularmente conhecida como castanha, de larga utilização culinária. Além do fruto, a casca da árvore é também utilizada como adstringente e tônico. 0 tronco do cajueiro produz uma resina amarela, conhecida por goma do cajueiro, que pode substituir a goma arábica, usada na indústria do papel e farmacêutica. Sua madeira é durável e de coloração rosada. As flores são especialmente melíferas e têm propriedades tônicas, já que contêm anacardina. Da seiva produz-se tinta. A raiz tem propriedades purgativas.

\section{Escopo}

Para pesquisa nos bancos de dados foram utilizadas os termos "caju”", "cajueiro", "cashew", "cashew tree*", "Anacardium occidentale*" em relação ao uso médico, veterinário e higiene. Nesta busca foram utilizadas as bases de dados Espacenet, Uspto e INPI. Inicialmente, a pesquisa encontrou 193 patentes na base de dados brasileira, INIPI, 1207 patentes da base européia, Espacenet, e 177 patentes na base dos Estados Unidos, Uspto, totalizando 1577 patentes selecionadas em dezembro de 2008.

Ao restringir a pesquisa apenas às patentes com aplicações contidas na classe A61, correspondente as ciências médicas, veterinárias e higiene, obteve-se 8 patentes na base INPI, 3 na base Uspto e 54 na base Espacenet, totalizando 65 patentes.

Tabela de pesquisa por palavras-chave

\begin{tabular}{llll}
\hline Palavras - chave & INPI & Espacenet & USPTO \\
\hline caju* $^{*}$ & 62 & 54 & - \\
cajueiro* $^{*}$ cashew* $^{*}$ & 126 & 2 & - \\
cashew* tree* $^{*}$ & 3 & 1119 & 1 \\
Anacardium occidentale & 2 & 10 & - \\
\hline
\end{tabular}




\section{Resultados e Discussão}

1. Evolução Anual de Depósitos de Patentes

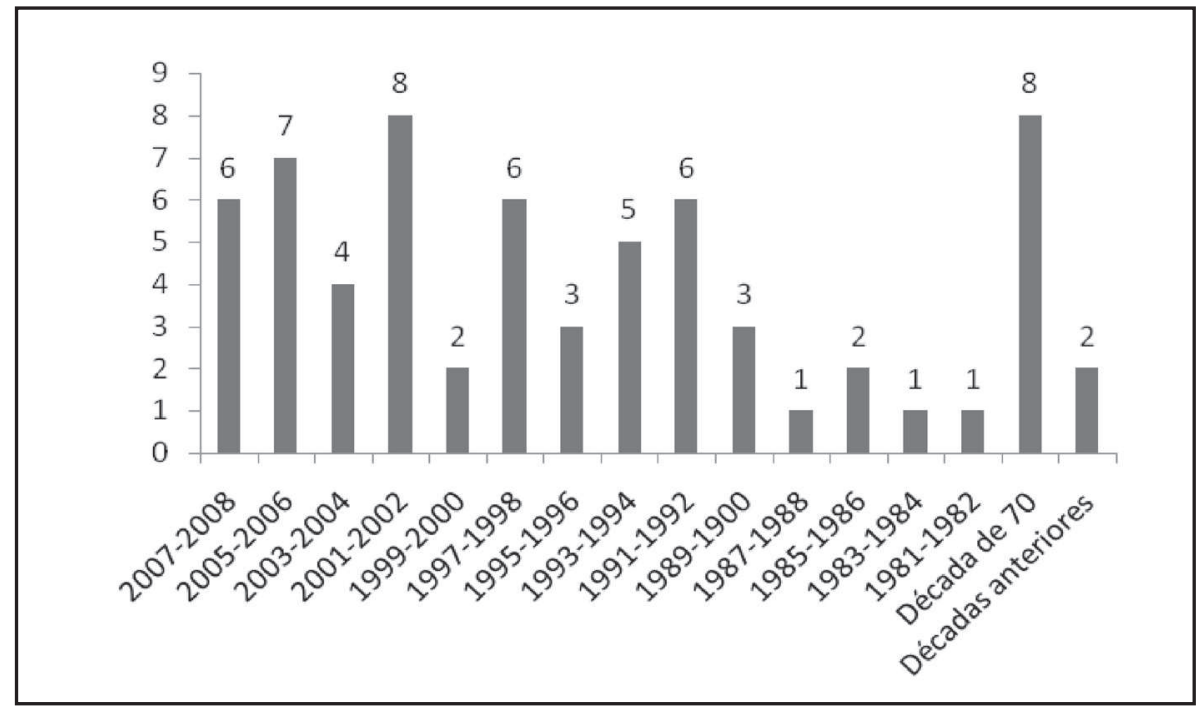

\section{Patentes por País/Organização}

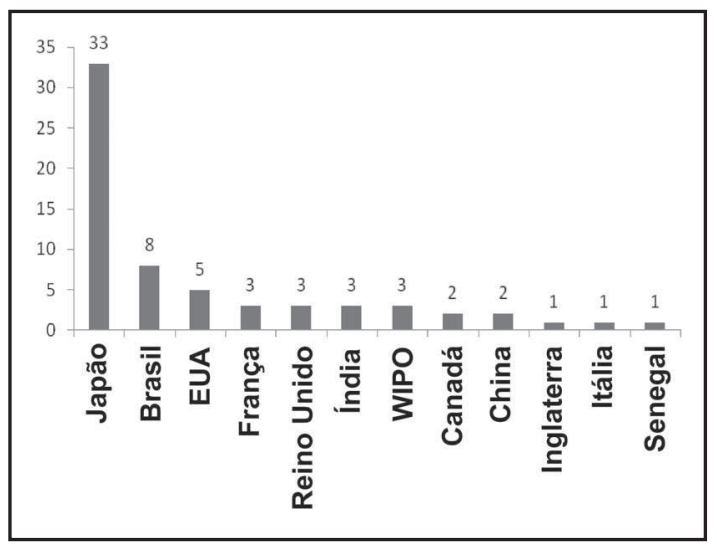

3. Patentes por Principais Inventores

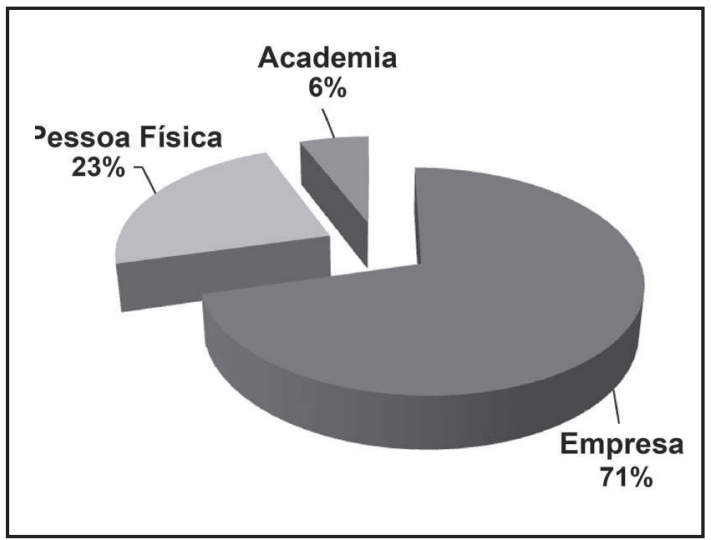

\section{Patentes por Empresa}

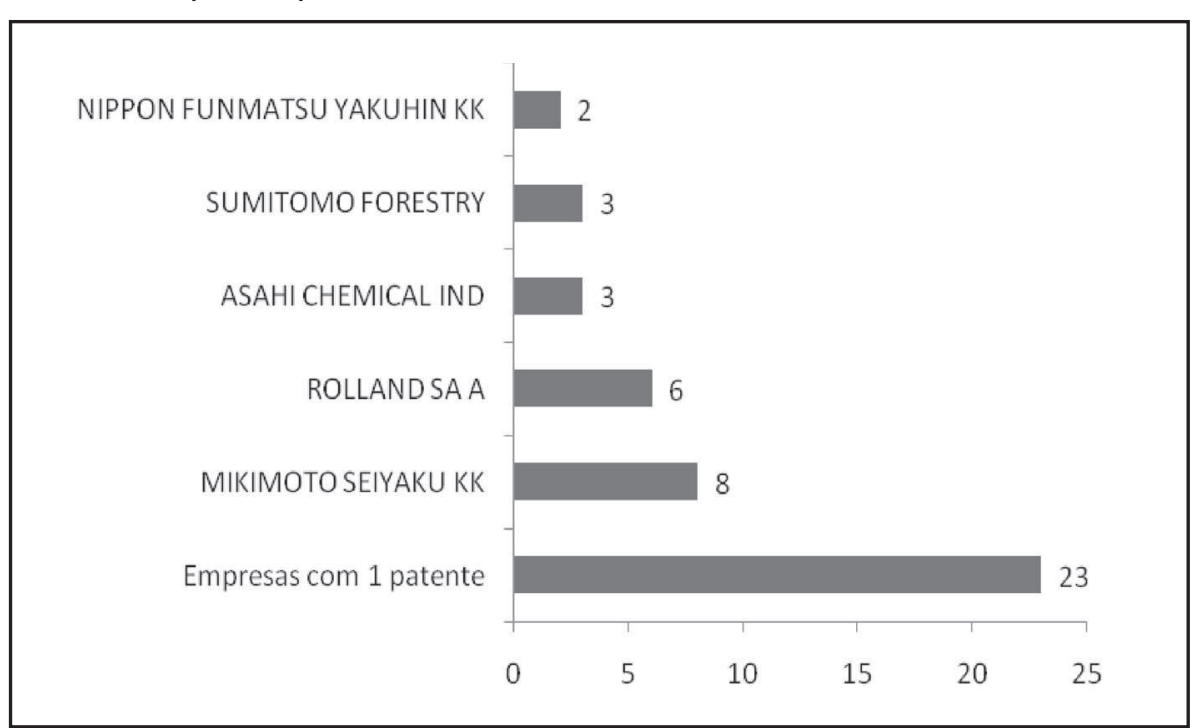


5. Principais Usos das Patentes

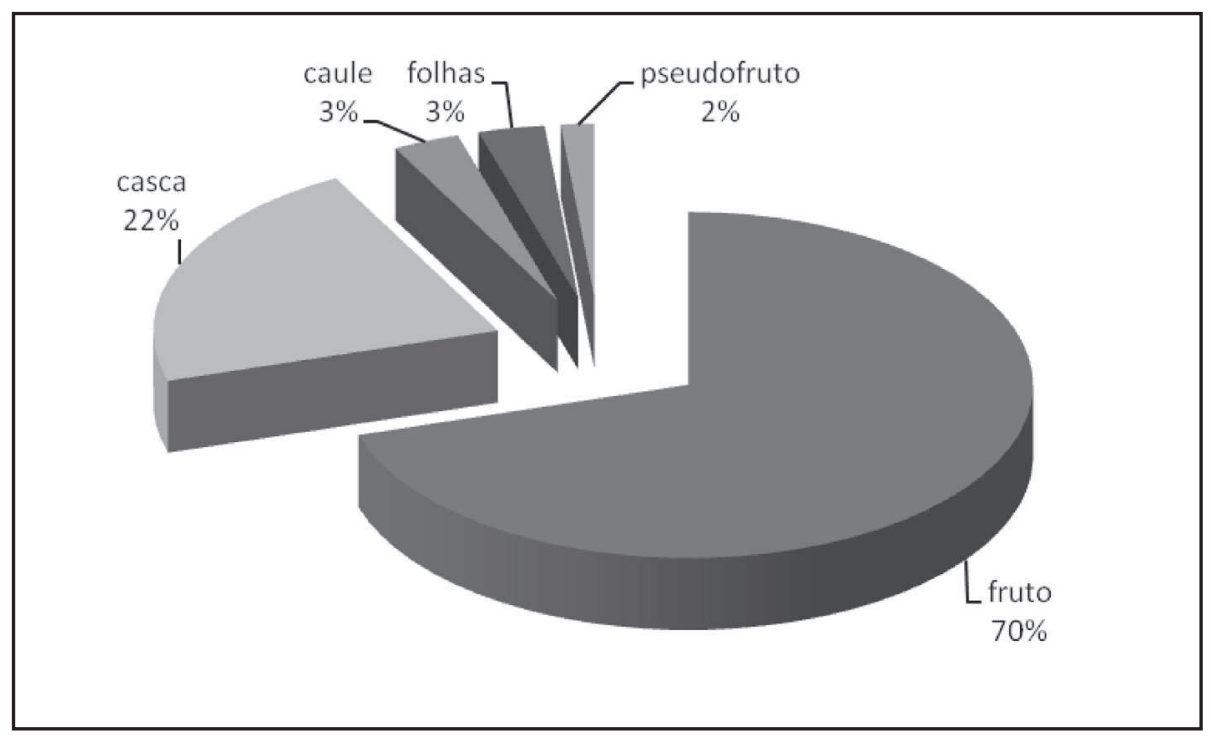

6. Distribuição por Código de Classificação Internacional

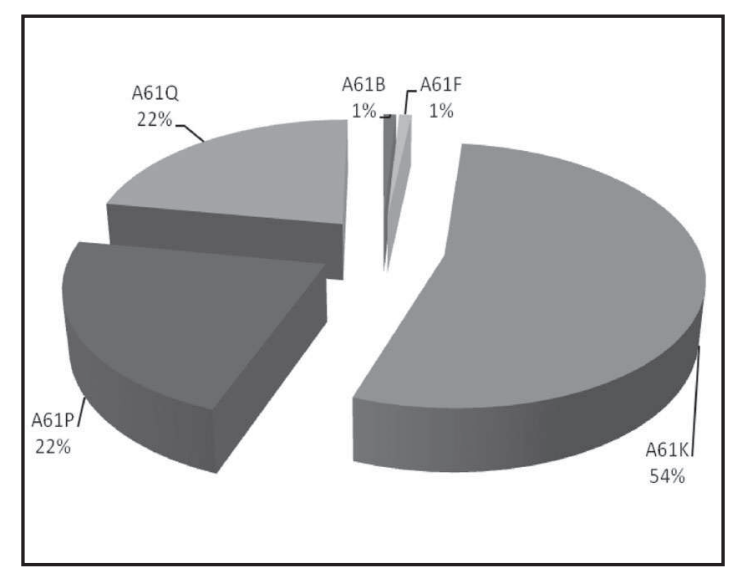

\section{Conclusões}

Houve um aumento no depósito de patentes a partir da década de 90 , porém com progressão cronológica bastante irregular. As patentes são depositadas principalmente por empresas (71\%), com pouca participação da academia (6\%). O Japão é o maior detentor de patentes relacionadas ao cajueiro com 33 patentes, seguido pelo Brasil com 8 patentes. A japonesa Mikimoto Seiyaku KK foi a empresa mais representativa, apresentando um total de 8 patentes, sendo seguida pela multinacional
Rolland SA A, com 6 patentes, entretanto a maioria, 23 patentes, pertencem a empresas que depositaram apenas uma patente. 0 fruto foi a parte do cajueiro mais utilizada nas patentes analisadas $(70 \%)$, com pouca utilização do pseudofruto (2\%) e nenhuma das flores e raiz. A finalidade mais reivindicada pelas patentes foi relativa a preparações médicas, odontológicas ou higiênicas, representando $54 \%$ do total, sendo uma consequência do escopo da busca.

Tonicley Alexandre da Silva e Priscila Sousa Barcellos são alunos de mestrado em Ciências da Saúde da UFMA. Flavia Raquel Fernandes do Nascimento e Rosane Nassar Meireles Guerra são Professoras do Departamento de Patologia da UFMA. 